RU Двусмысленность как прием создания комизма в немецкоязычном интернет-меме

\author{
Рохлина Т. А.
}

\begin{abstract}
Аннотация. Цель исследования - выявить языковые средства реализации приема двусмысленности в создании комического эффекта в немецкоязычном интернет-меме. Научная новизна исследования заключается в том, что языковая репрезентация комизма в меме посредством двусмысленности изучается впервые на материале немецкоязычного мема, двусмысленность рассматривается не только с позиций структурного, но и когнитивного подхода. В результате доказано, что двусмысленность в совокупности с эффектом обманутого ожидания является одним из средств создания комизма в немецкоязычном меме; специфика языковой репрезентации комического эффекта обнаруживается на разных языковых уровнях, а также имеет определенные когнитивные основания.
\end{abstract}

\title{
EN Ambiguity as a Technique for Creating Comicality in a German-Language Internet Meme
}

\author{
Rokhlina T. A.
}

\begin{abstract}
The research aims to identify the linguistic means of implementing the ambiguity technique in creating a comical effect in a German-language Internet meme. The research is novel in that it is the first to study the linguistic representation of comicality by means of ambiguity in a meme, using the material of a German-language meme, to consider ambiguity not only from the standpoint of the structural approach but also the cognitive one. As a result, it has been proved that ambiguity in combination with the failed expectations effect is one of the means of creating comicality in a German-language meme; the specifics of linguistic representation of the comical effect is found at different language levels and also has certain cognitive foundations.
\end{abstract}

\section{Введение}

Несмотря на существование обширных исследований комического в литературоведении и лингвистике, изучение этого феномена не теряет своей актуальности. В последнее время в связи с широким распространением цифровой среды коммуникации развиваются новые жанры и типы текста и дискурса, в которых обнаруживаются особенности выражения комизма. В данной работе мы обращаемся к такому типу дискурса, как интернет-мем, и рассматриваем языковые средства репрезентации комического в немецкоязычных мемах. Актуальность настоящей темы исследования обусловлена необходимостью изучить языковые средства репрезентации двусмысленности, участвующие в создании комического эффекта в немецкоязычном интернет-меме.

Для достижения поставленной цели необходимо решить ряд задач: 1) выделить из всего многообразия немецкоязычных мемов исследуемую группу; 2) обосновать целесообразность рассмотрения двусмысленности как приема создания комического эффекта в немецкоязычном меме; 3) выявить конкретные языковые средства, при помощи которых создается двусмысленность в исследуемой группе мемов и составить их классификацию.

Методы исследования: дискурсивный анализ, когнитивная интерпретация, семантико-стилистический метод.

Теоретической базой послужили исследования мемов и комического (Р. Докинз [3], С. В. Канашина [4; 5], О. А. Никитина, О. А. Гудкова, Ф. Зандер [6]), труды в области немецкой стилистики и лексикологии, исследования приемов двусмысленности и эффекта обманутого ожидания (Э. Г. Ризель, Е. И. Шендельс [7], Я. Славиньский [10], И. В. Арнольд [2]). 
Большинство отечественных исследований комического эффекта в мемах были проведены на материале английского и русского языков, немецкоязычные мемы мало изучены в русской германистике, поэтому практическая значимость работы заключается в ее вкладе в имеющиеся материалы по стилистике и лексикологии немецкого языка, лингвокультурологии, в изучение немецкоязычного полимодального дискурса.

\section{Основная часть}

Интернет-мемы вызывают интерес у социологов, культурологов и лингвистов с конца первого десятилетия XXI в., и уже появилось большое количество определений данного термина, однако все они восходят к понятию и определению мема, которые ввел британский ученый Ричард Докинз в 1976 г. в книге «Эгоистичный ген» [3]. Мем рассматривается как поликодовый текст [1; 8] и как полимодальный дискурс [4; 6]. Полимодальность отмечается как неотъемлемая черта мемов, хотя существуют и мономодальные мемы. В настоящей статье мы рассматриваем только полимодальные немецкоязычные мемы, состоящие из невербального и вербального компонентов, и взаимодействие в них языковых и неязыковых средств, создающее комизм.

Анализируемые мемы взяты из сети Instagram, которая является социальной сетью не политического, а развлекательного характера, поэтому в область нашего рассмотрения попали статичные развлекательные мемы (случайная выборка из 300 мемов в поиске по хештегу \#deutschememes) [17].

Поскольку мемы являются типом полимодального дискурса, то их комизм создается взаимодействием вербальных и невербальных средств. Однако в разных мемах роль вербальной или невербальной составляющей в создании комического эффекта может быть разной.

Языковая игра, в основе которой лежит двусмысленность, является распространенным стилистическим приемом создания комического эффекта в художественной литературе и публицистике. Двусмысленность рассматривается как разновидность языковой игры, как стилистическая фигура, основанная на многозначности слова или омонимии, которая реализуется только в контексте, когда становится возможной и очевидной такая языковая игра [7, с. 254-255]. В анализируемой выборке комический эффект, создаваемый двусмысленностью, встретился в 7\% мемов.

Во всех случаях комизм, создаваемый двусмысленностью, усиливается эффектом обманутого ожидания. Обманутое ожидание как прием создания комического эффекта связывается с нарушением различных стереотипов - социальных, языковых, стереотипов мышления, поведения и др. [9, с. 37]. Нарушения ожидания несут наибольшую информацию [10, с. 270], и, следовательно, сильнее воздействуют на адресата сообщения [2, с. 70].

Эффект обманутого ожидания используется в меме как мощное средство привлечения внимания и является неотъемлемой характеристикой жанра [5, с. 12-13]. Это объясняется другими жанровыми особенностями интернет-мема: адресностью, направленностью на интернет-пользователя, тенденцией удивить и заинтриговать его. Прием обманутого ожидания «позволяет предложить читателю неожиданную развязку, непредвиденный поворот событий, при этом текстовый ряд зачастую развивается от серьезного к смешному, т.е. вначале заявлена важная тема, которая переходит в комичную развязку с эффектом обманутого ожидания» [Там же, с. 9-10].

Совокупность приемов обманутого ожидания и языковой игры, построенной на двусмысленности, служит созданию комического эффекта в меме и получает конкретные языковые репрезентации.

Двусмысленность в меме создается вербальными и невербальными средствами, иногда преобладает один или другой компонент, но в большинстве случаев мы наблюдаем их тесное взаимодействие. Мы выделяем две подгруппы мемов по степени участия обоих компонентов в репрезентации комизма.

1. Мемы, в которых комический эффект выражен преимущественно в вербальном компоненте.

Такие мемы по содержанию и выражению комизма приближаются к современному анекдоту - «краткому устному рассказу с остроумной концовкой» [11, с. 17] - и имеют невербальный компонент, усиливающий комический эффект.

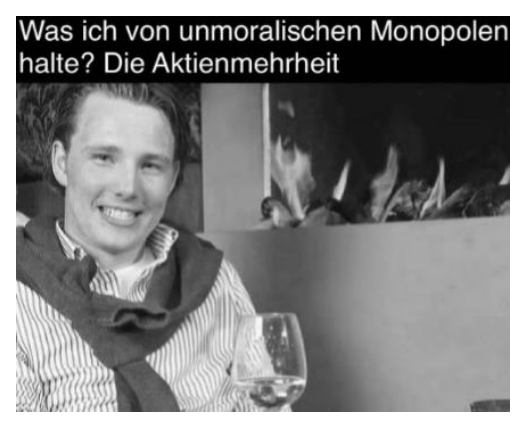

Рисунок 1

На Рис. 1 представлен мем, в котором игра слов основана на разных значениях полисемичного глагола "halten": 1. ergriffen, gefasst haben und nicht loslassen; festhalten [13] / схватить и не выпускать; удерживать. 2. über jemanden, etwas in bestimmter Weise denken, ein bestimmtes Urteil haben [Ibidem] / о ком/чем-л. думать определенным образом, иметь определенное мнение (здесь и далее приводятся только те значения полисемичных 
слов, которые участвуют в создании двусмысленности). В начале фразы на передний план выдвигается второе из указанных значений глагола: “Was ich von unmoralischen Monopolen halte?” / «Что я думаю о безнравственных монополиях?». Ответ на данный вопрос (“Die Aktienmehrheit” / «Контрольный пакет акций») выдвигает на передний план первое из указанных значений, и смысл фразы меняется: «Что я имею/держу от безнравственных монополий? Контрольный пакет акций». Без невербальной составляющей комический эффект не пропал бы, однако изображение богатого студента-экономиста (мем “BWL-Justus” [12]) добавляет высказыванию саркастическую окраску. Молодой человек на картинке смотрит прямо в объектив камеры, что придает всему тексту диалогичность, и сарказм, таким образом, адресован непосредственно реципиенту.

Данная подгруппа является небольшой и составляет 10\% рассматриваемой группы. Это объясняется тем, что при выражении комического эффекта преимущественно вербальными средствами графический компонент остается практически незадействованным, что лишает смысла полимодальность мема.

2. Мемы, в которых комический эффект реализуется в равном взаимодействии вербального и невербального компонентов.

Выражение двусмысленности в данной подгруппе мемов имеет большее разнообразие, чем в предыдущей, поскольку в реализацию данного приема вовлечены вербальные и невербальные средства, и выдвижение на передний план того или иного значения слова/выражения обусловлено как вербальным, так и графическим компонентом.

А) Омофония.

Комический эффект основан на фонетической омонимии слов и эффекте обманутого ожидания при распознавании адресатом языковой игры.

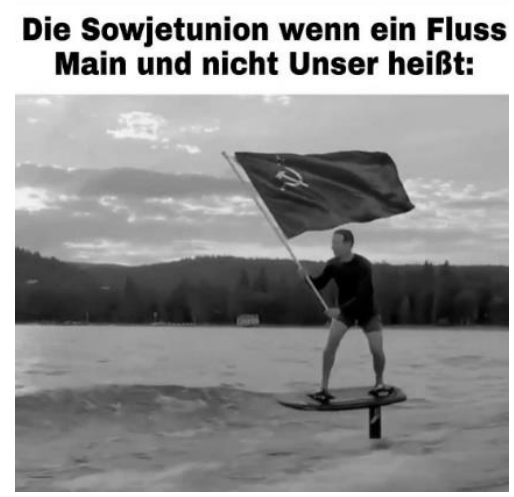

Рисунок 2. «Советский Союз, когда река называется Майн, а не Наш:»

На Рис. 2 представлен мем с фонетической омонимией слов “Маin” / «Майн» (название реки) и “теin” / «мой» в вербальном компоненте. На картинке - Марк Цукерберг, держащий развевающийся флаг Советского Союза (отсылает адресата к прецедентной ситуации, вследствие которой возник мем, изображающий Марка Цукерберга с флагом США [18]); возможная интерпретация картинки - прославление коммунизма. Контекст, необходимый для понимания языковой игры, создается вербально (die Sowjetunion, Unser) и невербально (флаг Советского Союза), адресату становится очевидной оппозиция “mein - unser”, которая выражает противопоставление индивидуалистического коллективному. Комический эффект от языковой игры усиливается нелепостью ситуации, представленной в графическом компоненте - неожиданным сочетанием символа коммунизма с окружающей обстановкой, замена флага капиталистической страны на флаг СССР.

Б) Морфемная омонимия.

Комизм мемов основан на языковой игре с использованием формального совпадения морфем.

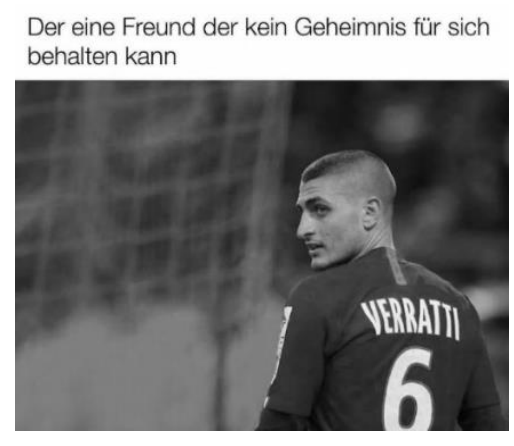

Рисунок 3. «Друг, который не умеет хранить секреты - Верратти»

Комический эффект мема на Рис. 3 основан на омонимии корней у немецкого глагола “verraten” - etwas, was geheim bleiben sollte, wovon nicht gesprochen werden sollte, weitersagen, preisgeben [15] / рассказывать, 
разглашать то, что должно оставаться в тайне, о чем нельзя говорить - и фамилии итальянского футболиста Марко Верратти (Verratti).

В) Полисемия.

Комический эффект основан на неожиданном выдвижении на передний план иного значения полисемичного слова, не того, на которое указывает первоначальный (вербальный) контекст. Как правило, в данной группе мемов контекстом для выдвижения второстепенного значения является визуальный компонент.

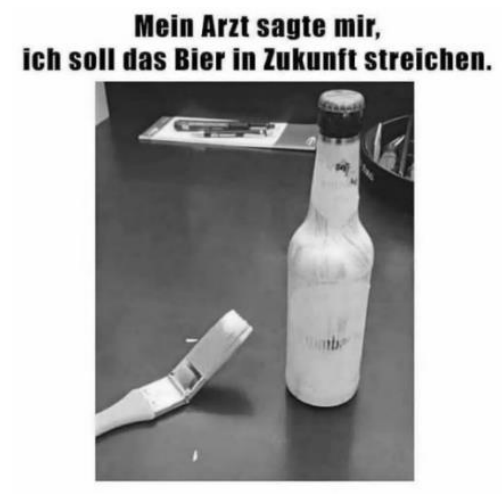

Рисунок 4

Первоначально вербальный компонент мема на Рис. 4 можно интерпретировать следующим образом: «Мой врач велел мне отказаться от пива». Комический эффект основан на разных значениях полисемичного глагола "streichen": 1. mithilfe eines Pinsels o. Ӓ. mit einem Anstrich versehen; anstreichen [14] / при помощи кисти и т.п. наносить краску, окрашивать. 2. (etwas Geschriebenes, Gedrucktes, Aufgezeichnetes) durch einen oder mehrere Striche ungültig machen, tilgen; ausstreichen [Ibidem] / (что-л. написанное, напечатанное, записанное) удалять, вычеркивать одной или несколькими чертами. Контекст рекомендации врача в вербальном компоненте предполагает выдвижение на передний план второго из указанных значений; невербальный компонент выдвигает на передний план первое значение, создавая противоречие. Смысл сообщения - автор ведет себя в рамках предписания, следует рекомендации врача, но не хочет отказываться от пива.

Г) Буквализация фразеологизма или прецедентного высказывания.

Комизм строится на эффекте обманутого ожидания от разложения фразеологического выражения или прецедентного высказывания на составные части и его буквальной интерпретации.

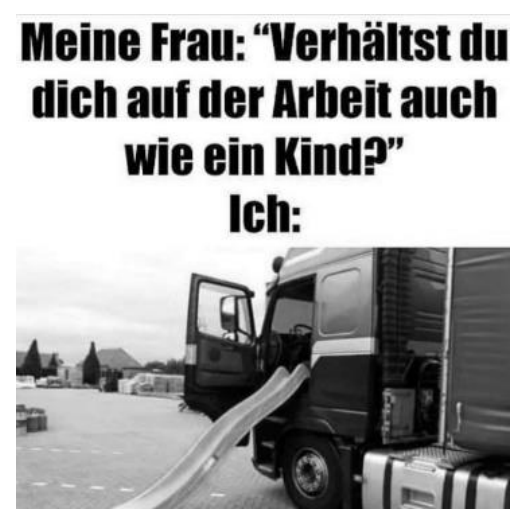

Рисунок 5. «Моя жена: “На работе ты тоже ведешь себя как ребенок?” Я:»

Сравнительный фразеологизм, использованный на Рис. 5, “sich wie ein Kind verhalten”, означает «вести себя как ребенок, быть несерьезным». Комический эффект основан на взаимодействии вербальной и невербальной составляющих и эффекте обманутого ожидания, реализуемого в невербальной части: изображение детской горки, приставленной к двери кабины фургона, указывает на буквальное понимание фразеологизма.

Д) Разложение слова на компоненты.

Наиболее часто данный вид языковой игры применяется при разложении на компоненты фамилий известных личностей.

На Рис. 6 представлен мем, построенный по контрастивной модели [4, с. 18], где противопоставлены два объекта - “stiller Fluss” / «спокойная река» и немецкий политик Карл Лаутербах, фамилия которого, будучи разложенной на два компонента, приобретает двусмысленность в данном контексте - контрастивная модель противопоставления объектов на картинке применяется к именованию этих объектов с помощью антонимов “still” - “laut” / «тихий» - «громкий», контекстуальных антонимов "Fluss” - “Bach” / «река» - «ручей» и создает комический эффект. 


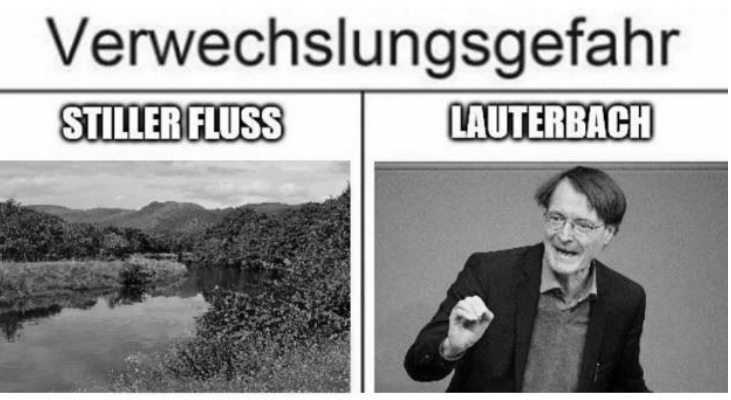

Рисунок 6. «Риск смешения: Спокойная река - Лаутербах (досл. 'громкий ручей'»

Е) Антифразис.

Вербальный компонент содержит фразу, двусмысленность, а именно противоположный первоначальному смысл, который становится очевидным адресату только сквозь призму невербального компонента.

\section{Die Werbung der Bank: "Wir vertrauen unseren Kunden komplett."}

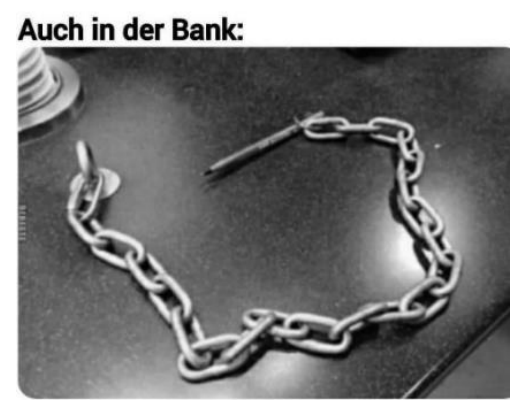

Рисунок 7. «Реклама в банке: “Мы полностью доверяем нашим клиентам”. Также в банке:»

Невербальный компонент на Рис. 7 представляет собой картинку с привязанной к столу шариковой ручкой, которая демонстрирует недоверие, усиленное изображением толстой цепи, и создает контекст, благодаря которому значение глагола “vertrauen" - in jemanden, etwas sein Vertrauen setzen; auf jemanden, etwas bauen; sicher sein, dass man sich auf jemanden, etwas verlassen kann [16] / оказывать доверие кому/чему-л.; полагаться на кого-л.; быть уверенным, что на кого/что-л. можно положиться - приобретает иронический оттенок.

Ж) Нарушенная кореференция.

Двусмысленность возникает вследствие обращения коммуникантов, изображенных на меме, к разным объектам действительности, имеющим одинаковое именование и одно и то же словарное значение.

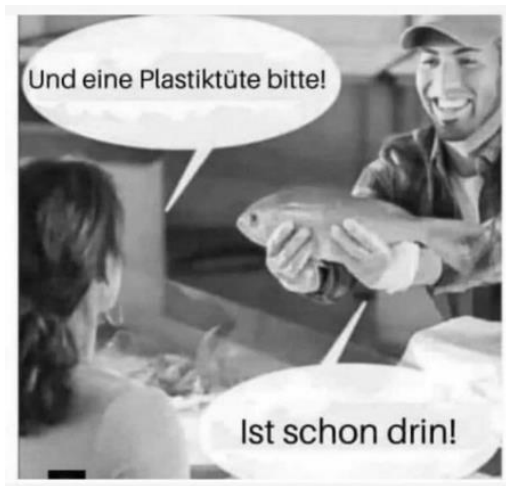

Рисунок 8. «И пластиковый пакет, пожалуйста! - Уже внутри!»

На Рис. 8 изображена ситуация покупки рыбы, в которой коммуниканты - девушка-покупатель и молодой человек-продавец - обращаются к разным объектам действительности. Несмотря на то, что объекты имеют одно именование - “eine Plastiktüte” / «пластиковый пакет», - пресуппозиции каждого из коммуникантов при этом разные. Покупатель имеет в виду пакет для покупок, чтобы завернуть в него рыбу, продавец - пластиковый пакет, который уже был использован, выброшен с отходами в воду и проглочен рыбой. Комизм этого мема призван не только выполнять развлекательную функцию, но и привлечь внимание к экологическим проблемам. 


\section{Заключение}

Таким образом, мы приходим к следующим выводам. Несмотря на то, что прием двусмысленности не является основным в создании комического эффекта в немецкоязычном интернет-меме, все же, как показал материал, он применяется не в единичных случаях, соответственно, можно говорить о периодическом использовании данного приема. Было отмечено, что во всех случаях двусмысленность в меме реализуется вместе с эффектом обманутого ожидания, усиливающим комизм мема. В результате исследования мемов, в которых был использован прием двусмысленности в совокупности с обманутым ожиданием, мы классифицировали их по двум группам в зависимости от степени участия вербального и невербального компонентов в создании комического эффекта. Группа мемов, в которой наличествует равнозначное участие вербального и невербального компонентов в создании комизма, отмечается разнообразием средств выражения языковой игры на основе двусмысленности. Описываются конкретные лексические, стилистические и текстограмматические средства создания двусмысленности. Ввиду малоизученности немецкоязычных интернет-мемов представляются перспективными дальнейшее изучение и классификация языковых средств репрезентации комизма в данном типе дискурса.

\section{Источники | References}

1. Аникина Т. В. Интернет-мем в условиях современной коммуникации // Новая наука: опыт, традиции, инновации. 2016. № 8-2. С. 54-58.

2. Арнольд И. В. Семантика, стилистика, интертекстуальность: сб. статей / науч. ред. П. Е. Бухаркин. СПб.: Изд-во С.-Петерб. гос. ун-та, 1999. 443 с.

3. Докинз Р. Эгоистичный ген. М.: АСТ: Corpus, 2013. 512 с.

4. Канашина С. В. Интернет-мем как новый вид полимодального дискурса в интернет-коммуникации (на материале английского языка): автореф. дисс. ... к. филол. н. М., 2016. 27 с.

5. Канашина С. В. Эффект обманутого ожидания в интернет-мемах как особая коммуникативная стратегия // Вестник Томского государственного педагогического университета. 2017. № 10 (187). С. 9-14.

6. Никитина О. А., Гудкова О. А. Зандер Ф. Интернет-мем как мультимодальный феномен немецкоязычного интернет-дискурса // Язык и культура. 2018. № 43. С. 74-87.

7. Ризель Э. Г., Шендельс Е. И. Стилистика немецкого языка. М.: Высшая школа, 1975. 316 с.

8. Рохлина Т. А. Материальное воплощение интернет-мема как поликодовый текст // Когнитивные исследования языка. 2018. № 34. С. 657-660.

9. Рохлина Т. А. Языковая репрезентация комического в жанрах немецкой смеховой культуры (на примере немецкого прозаического шванка): дисс. ... к. филол. н. М., 2016. 174 с.

10. Славиньский Я. К теории поэтического языка // Структурализм «за» и «против»: сб. статей / под ред. Е. Я. Басина, М. Я. Полякова. М.: Прогресс, 1975. С. 256-277.

11. Словарь литературоведческих терминов / ред.-сост. Л. И. Тимофеев, С. В. Тураев. М.: Просвещение, 1974.513 с.

12. https://www.bedeutungonline.de/bwl-justus/(дата обращения: 27.07.2021).

13. https://www.duden.de/rechtschreibung/halten (дата обращения: 24.07.2021).

14. https://www.duden.de/rechtschreibung/streichen (дата обращения: 24.07.2021).

15. https://www.duden.de/rechtschreibung/verraten (дата обращения: 24.07.2021).

16. https://www.duden.de/rechtschreibung/vertrauen (дата обращения: 24.07.2021).

17. https://www.instagram.com/explore/tags/deutschememes/(дата обращения: 15.07.2021).

18. https:/www.ladbible.com/entertainment/celebrity-mark-zuckerberg-flag-waving-surfing-video-sparks-memes20210705 (дата обращения 27.07.2021).

\section{Информация об авторах | Author information}

RU Рохлина Татьяна Александровна ${ }^{1}$, к. филол. н.

${ }^{1}$ Рязанский государственный радиотехнический университет имени В. Ф. Уткина

EN Rokhlina Tatiana Alexandrovna ${ }^{1}, \mathrm{PhD}$

${ }^{1}$ Ryazan State Radio Engineering University n. a. V. F. Utkin

${ }^{1} t_{-}$rokhlina@mail.ru

\section{Информация о статье | About this article}

Дата поступления рукописи (received): 28.07.2021; опубликовано (published): 30.09.2021.

Ключевые слова (keywords): комическое; эффект обманутого ожидания; двусмысленность; языковая игра; мем; the comical; failed expectations effect; ambiguity; language game; meme. 